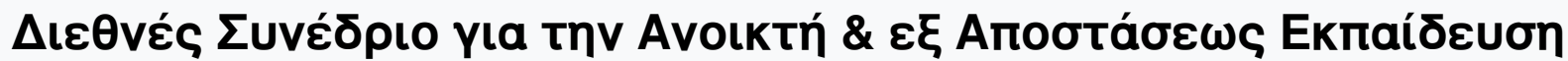

Tón. 7, Ap. 1A (2013)

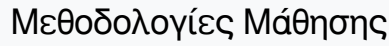

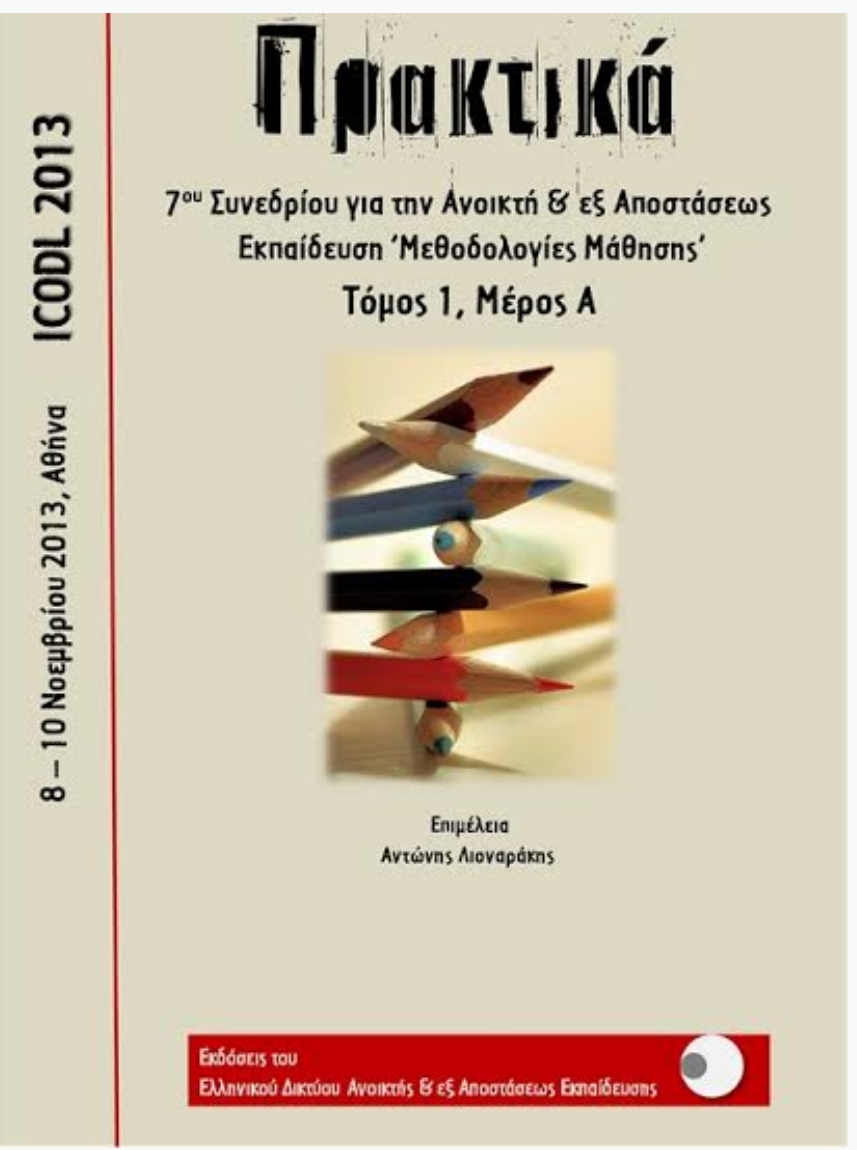

Emancipatory Technology Enhanced Learning' bridging whatever technology divides

Maria Fragkaki

doi: $10.12681 /$ icodl. 533

\author{
do.12681/icod1.533
}




\title{
Emancipatory Technology Enhanced Learning' bridging whatever technology divides
}

\author{
Maria Fragkaki \\ Educator, Researcher, Teacher-Counselor \\ "Computer Technology Institute and Press Diophantus" \\ fragakim@otenet.gr
}

\begin{abstract}
One of the reasons put forth for utilizing Technology Enhanced Learning (TEL) is to cope with the so-called 'digital divide': computers and networks at schools are supposed to bridge this new social inequality, just like universal literacy from schooling helps to deal with social inequalities in general. In this paper we argue that the 'digital divide' constitutes a much subtler social discrimination than the classic economic and class inequalities; it is much more difficult to deal with than straightforward economic or more complex cultural and class inequities. This is clearly reflected in the type of TEL utilization in education, rather than its amount. Unqualified use of computers and networks in schools might sharpen or hide the 'digital divide' rather than alleviate it. And this causes a 'knowledge divide'. Furthermore, when we are talking about the knowledge divide's impacts upon society we are talking about a 'social divide'. TEL has a clear social class effect, whether its proponents realize it or not, whether its implementers are consciously aware of the effects or not. Thus, the new literacies may widen social schisms not only because they increase the distance between the haves and the have-nots, just like any other technology. What the new literacies offer may also widen social schisms in qualitative ways. In this paper we give examples of concrete educational practices which, while involving TEL use in schools, may well broaden the 'digital divide'. We show that more TEL is not always better and that it is easy to pay lip service to high educational curriculum goals when the actual practice of TEL is in fact a disservice. Measuring and assessing the long term social effects of TEL is particularly difficult. We propose, however, a systematic way to observe short term effects from its utilization in schools and present the example of an elementary school in Greece.
\end{abstract}

Keywords: Emancipatory Technology Enhanced Learning, digital divide, social divide, knowledge divide

\section{Introduction}

One of the reasons put forth for utilizing TEL is to cope with the so-called digital divide': computers and networks at schools are supposed to bridge this new class inequality, just like universal literacy from schooling helps to deal with social inequalities in general. It may be not clear, but it certainly is real. It may not be clear exactly what the 'digital divide' is, but we have seen it emanate in social classes and at least teachers have certainly observed its appearance in school classes. 


\section{From the viewpoint of educational policy directives}

If you look into the educational policy directives of the past several years you can somehow encapsulate them. The integration of TEL in the educational process is considered to have been proven, at an international level, for important scientific, teaching and learning purposes. And TEL use in schools is desirable in order to deal with the social divide. The integration of Information Communication Technology (ICT) in the educational process does not concern only their use, but it also involves how educators can capitalize on them in the educational process. This means creating the infrastructure in schools, the computers and the networks and preparing the teachers to use them. So, in regards to the "digital divide", this means integrating TEL in schools and this has certainly been a political directive. So, is it just a political advertisement or is it an educational directive? Furthermore, to what extent is there actual pedagogical truth?

\section{From the viewpoint of analysts}

In a recent piece, DiMaggio and Hargittai (2001), two of the most astute analysts of the sociology of the Internet discuss the issue of the 'digital divide'. They assert that since nowadays Internet diffusion rates have increased, scholars should shift their attention from the 'digital divide'-inequality between the haves and the have-nots based on dichotomous measures of Internet access - to digital inequality, by which they mean differences among people with physical access to the Internet. Digital inequality, from their perspective, encompasses five (5) main variables: technical means (inequality of bandwidth); autonomy (whether users log on from home or at work, monitored or unmonitored, during limited times or at will); skill (knowledge of how to search for, or download information); social Support (access to advice from more experienced users); and purpose (whether they use the Internet for increase of economic productivity, Improvement of social capital, or consumption and entertainment).

\section{From the viewpoint of a research vignette}

There is a vignette that we think can help us somehow to comprehend the issue that social and educational problems can be addressed by providing computers and Internet accounts as increasingly problematic. In 2000 the government of New Delhi, in collaboration with an information technology corporation, established a project, known as the 'Hole-in-the-Wall' experiment (Figure 1), to provide computer access to the city's street children, setting up an outdoor computer kiosk with monitors through holes in the walls with an Internet connection, in one of the poorest slums of New Delhi, but without teachers and instructors. Although the government offered a model in order to bring India's and the world's urban poor into the computer age, children did learn to manipulate the joysticks and buttons, but almost all their time was spent drawing with paint programs or playing computer games, without acquiring "21 century skills" (OECD, 2013) that would help them achieve better lives. Parents and the community came to realize that minimally invasive education was, in practice, minimally effective education (Warschauer, 2003). 


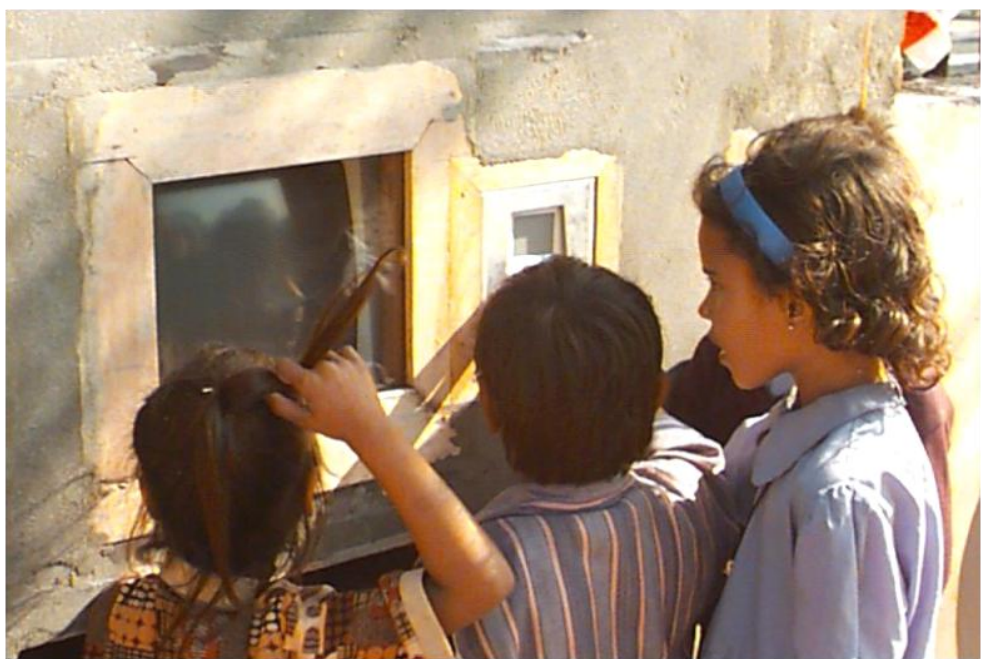

Figure 1: 'Hole-in-the-Wall' experiment

It is a fact that digital literacy and digital fluency are important concepts in the contemporary world. There are fundamental cognitive differences in individuals who are literate and who are not, resulting in a great literacy divide at both the individual and societal levels. But the manipulation of the computers is not digital fluency. It is like to keeping a pen and just writing lines on a paper without a reason. Literacy and ICT involve not only receiving information but also organizing it, analyzing it, criticizing it and producing it.

\section{Rethinking \& wondering}

Rethinking the 'digital divide' the program from the vignette described above was motivated by a sincere attempt to improve students' cognitive skills through TEL and generally people's lives. But, it seems that meaningful access to ICT implies far more than merely providing computer resources and Internet connections. However, there seems to be a strong need to integrate ICT in the educational process for social reasons, since as is mentioned in the UNESCO "Short-Term Action Plan", this must be able to contribute to the better understanding of global problems and their interplay. TEL should provide students with the required knowledge and ability in order to understand, counter and resolve these problems and to excite the interest and will that will lead to action (Europe 2012, Eurostat 2013, EESC 2013, Eurydice 2012, OECD 2013). The EU national directives and indicators over the years are a very good example for this need, allowing national directives in educational systems but also provide a general direction.

In this paper, we will see the shift from access to an infrastructure of ten or fifteen years ago to more qualitative teaching and learning, which however has not reached the schools, and we can say that it has not even reached the mainstream undervalued education of teachers. Content and language, literacy and education, different degrees of access to information technology (Cisler, 2000, Warschauer, 2003), and community and institutional structures must all be taken into account if meaningful access to new technologies is to be provided. So the question we will deal with in this paper is to what extent and in what way will using ICT in school alleviate the 'digital divide', or maybe sharpen it or just hide it.

\section{Definitions: What is the 'digital divide'?}

A 'digital divide' (http://en.wikipedia.org/wiki/Digital_divide) is an economic inequality between groups, broadly construed, in terms of access to, use of, or 
knowledge of Information Communication Technologies (ICT), (U.S. Department of Commerce, 1995, Chinn, Menzie \& Robert \& Fairlie, 2004 ). The divide within countries (such as the 'digital divide' in the United States) can refer to inequalities between individuals, households, businesses, and geographic areas at different socioeconomic and other demographic levels (UNESCO, 2002, Norris, 2001, Patricia, 2003), while the divide between countries is referred to as the global 'digital divide', which designates nations as the units of analysis and examines the gap between developing and developed countries on an international scale (Chinn, Menzie \& Robert W. Fairlie. 2004). Furthermore, there is the social inclusion, not only as an adequate share of resources but also as the participation in the determination of both individual and collective life chances. It overlaps with the concept of socioeconomic equality but is not equivalent to it. Conceptualization of the 'digital divide' is often given as follows (Hilbert, 2011, Buente, Wayne \& Robbie, 2008):

1. Subjects of connectivity, or who connects: individuals, organizations, enterprises, schools, hospitals, countries, etc.

2. Characteristics of connectivity, or which attributes: demographic and socioeconomic variables, such as income, education, age, geographic location, etc.

3. Means of connectivity, or connectivity to what: fixed or mobile, Internet or telephony, digital TV, etc.

4. Intensity of connectivity, or how sophisticated the usage: mere access, retrieval, interactivity, innovative contributions.

5. Purpose of connectivity, or why individuals and their cohorts are (not) connecting: reasons individuals are and are not online and uses of the Internet and ICT.

We realize that when we talk about the 'digital divide' we mean differences that affect people, and thus collective differences in society. And those differences concern social classes, countries, age groups, etc. Thus 'digital divide' is the collective differences in society that are related to digital technology or it is all due to digital technologies and this is not exactly the same thing. We can have differences due to digital technologies that are unrelated to digital technologies, for example, how well one understands something, due to availability of technologies but it's not related directly to this. It's not due to them, it's due to them but not related to them, or differences regarding how one deals with dangers related to digital technologies.

Since gender, age, racial, income, and educational gaps in the 'digital divide' have decreased compared to past levels, some researchers suggest that the 'digital divide' is shifting from a gap in access and connectivity to ICTs to a 'Knowledge Divide' (Graham, Mark 2011). A 'knowledge divide' concerning technology presents the possibility that the gap has moved beyond access and having the resources to connect to ICTs, to interpreting, understanding, reflecting and criticizing the information presented once connected (Fragkaki \& Hatzilacos, 2012). The concept of the 'knowledge divide' refers to the gaps in standards of living and economic development that exist between those who can find, create, manage, process, and disseminate information or knowledge, and those who are impaired in this process. According to a 2005 UNESCO World Report, the rise in the 21 st century of a global information society has resulted in the emergence of knowledge as a valuable resource, increasingly determining who has access to power (UNESCO, 2005). The rapid dissemination of information on a potentially global scale as a result of new information media and the globally uneven ability to assimilate knowledge and information has resulted in potentially expanding gaps in knowledge between individuals and nations. 


\section{Technological and Social Divides in Human History}

Is there anything new about social divides, regarding digital technologies? Don't we always have social divides in human history which are due to technologies? Browsing, for example, the famous book 'Guns, Germs and Steel: The Fates of Human Societies', we can see that Jared Diamond, professor of geography and physiology at the University of California, argues that the gaps in power and technology between human societies originate in environmental differences, which are amplified by various positive feedback loops. We know that the fundamental difference that has shaped human history is the basic technology of food production. So, every time we have a new technology, we have a dialectic effect. These new technological affordances potentially broaden the social schism between those who have and those have not. On the other hand those new technological affordances can again potentially reach much broader social segments (Fragkaki \& Hatzilacos, 2012).

Therefore, the 'social divide' produced by technological advance have these two sides. If, for example we go to the fundamental technology that has affected education - the printed book - we can see that on the one hand the fact that many more printed books were available than before, implied a much wider potential difference between those who could read them and those who could not read them, those who did have access to them and those who did not. On the other hand the fact is also true that we had many more and much - much cheaper books meant for a far larger segment of the population who was able to read. These issues pose complex problems, and reveal the unavoidable dilemma concerning ICT in poor and developing countries: without access to ICT struggling societies are in danger of further isolation, but that very access creates new forms of exclusion and colonization. The question is then: are there any alternatives? So, let's see what it is we claim regarding the initial question which is: 'does using ICT in school help alleviate the schism? Does it sharpen it or it just hide it?'

\section{Our Claims beyond Owner and Access}

1. Our first claim is that the 'digital divide' is a much subtler social discrimination than say economic or even the claim 'knowledge divide" or 'social divide'. It is much more difficult to handle than simple economic or more complex cultural and class distinctions. You cannot observe it easily, but at a more general level, the majority of societies and citizens, who do not possess the financial, social or cultural background of the "developed" countries, do not have the technological infrastructure and thus the potential and the corresponding skills to use and make use of the technologies, and as a result, ICTs cannot offer them the equal right to participate alongside the "modern" citizens, to communication and in making decisions that concern them. In this way, they are deprived of the opportunity for any essential participation in decisions and responsibilities regarding fundamental problems that concern themselves and the state. Consequently, while technology leaps ahead, it seems unable to defend citizens and democratic institutions.

2. The second claim is that what actually determines the resulting 'digital divide' from using ICT, is not as much the 'amount' or the 'access', as the 'type' of this education. And when we say 'amount' we mean in a simple manner 'amount' without 'quality'. And when we say 'access' we mean to have the opportunity to be 'qualitative'. And when we say 'type' we mean 'quality' and 'meaning', 'critical thought' and 'creative action'. And that 'type' 
depends a great deal on the educational framework, the learning profile of the educators, and it is determined by many different factors that relate more to their 'cognitive interests' (Habermas, 1972) of those participating in the process and to the wider, social, political environment, and less to the possibilities ICT offers (Fragkaki, 2008). And when we say 'cognitive interests' we the three primary cognitive areas in which human interest generates knowledge. These areas determine categories relevant to what we interpret as knowledge.

3. A more interesting and maybe controversial statement is that just using TEL within a unqualified use of computers and networks, may very well not only not alleviate the 'digital divide' but it might even sharpen it or just hide it. And this kind of use express an 'apathy' that most of the times cover up an 'ignorance' and hide 'rusty' pedagogical theories and transmissible methodologies. And not only because of course are politicians pain leap services to using the technologies in schools. But because the majority of educators just follow instructions and curricula that have been designed by "experts", who do possess the know-how to use software, programs, and systems, but do not have a critical-reflective outlook with a criticalconstructivist theoretical orientation. The aforementioned learning activities have not centered on the political, ethical, social and critical dimension of integrating ICTs. They have overlooked the need to develop the learners skills to constructively build on the mass of information that they can easily access by using technology, as well as the possibility to apply the functions of critical-reflective and creative thinking to manage compounded problems (Fragkaki \& Lionarakis, 2011) And that's why it is important to understand the effects of the teachers. Our final point is that TEL has a clear social class effect, whether its proponents realize it or not, whether its implementers are consciously aware of the effects or not. The potential of ICTs, whereas they facilitate access to information and support the communication and cooperation among citizens and societies, it seems that they cannot contribute, to a satisfactory degree, in managing complex social issues (Fragkaki, 2008). And this maybe the most important practical conclusion.

\section{Emancipatory Technology Enhanced Education: An approach to crisis alleviation}

The author suggests the Emancipatory Technology Enhanced Education (Emancipatory TEL), as an approach to alleviate these divides, seeking to explore the social, economic and political benefits it can provide for an individual and for a society (including the world society in a globalised context). In our opinion an emancipatory cognitive interest (Habermas, 1972) supports a 'type' of education that through ICT can alleviate the 'digital divide' that came from using ICT and transformed to a 'knowledge divide'. Epistemologically, it belongs to the CriticalDialectic Paradigm, and is in contrast to the technical cognitive interest, which basically targets "control" and "management". Nevertheless, it extends the notion of 'understanding' a situation ('practical cognitive interest'), to forming a 'critical consciousness' and to 'action', aiming at social change. Critical emancipatory action creates the conditions that provide the individual and teams, with the ability to recognize the limitations and the distortions that are imposed upon them by external factors and powers, and to aim for liberation and release from such situations. Emancipatory interest is not restricted only to personal transformation, but it is 
directed to social transformation, with a long-term view. No fundamental orientation, apart from the emancipatory can ensure the liberation of people from the control inflicted by the technical and the potential illusion of the practical. An illusion that occurs when individuals are not aware of the degree and the manner in which their understanding is distorted, by those who desire the recreation of the social status quo (Grundy, 2003, Carr \& Kemmis, 1997). For Habermas, 'emancipation is identified as autonomy, responsibility, justice, equality and action for social change. This position is founded on the dialectic concept of social determinism, which does not exclude individuality, singularity and free will, given that humans are not only determined by events, but they create them . The critical-dialectic view, acknowledges that there are 'objective' restrictions to social thought and action, which lie beyond the control of specific teams or individuals, and that there are 'subjective' restrictions, which people could change, if they could change the mechanisms with which these restrictions set boundaries and obstructions to their action. This implies not only understanding the restrictions and their sources, but also criticism and action in order to deal with them. So, is not data- is information, is not use- is utilization and much better is integration. Integration by a 'technical cognitive interest' that can sharpen 'digital divide' or utilization by a 'practical cognitive interest' that can just hide it, and utilization by an 'emancipatory cognitive interest', through Emancipatory Education that can alleviate the 'digital divide'. We need the theory, the environment, the tools, the scenarios and their evaluation in practice. ICT in Education can serve any purpose, learning theory and teaching method. We insist a specific purpose (namely alleviating the crisis); a specific learning theory (namely Emancipatory Technology Enhanced Learning paradigm to provide the theory and the pedagogy for alternative teaching options, aiming at autonomy, responsibility, justice, equality and action for social change and society's reconstruction) and a specific teaching method to match the purpose and the theory (namely critical-reflective technology enhanced methodology).

Main principles for planning an Emancipatory TEL paradigm:

- Emancipatory TEL means the integration of ICT in education within the framework of "emancipatory cognitive interest" (Habermas, 1972) with the goal of forming a critical consciousness in individuals and communities, aiming at autonomy, responsibility, justice, equality and action for social change (Carr \& Kemmis, 1997).

- The educational subjects are authentic and social concerning the learners themselves and the wider society in which they live. Educators have the opportunity to co-develop, together with their learners, the content of the educational material and the educational process.

- Learners function as vehicles and not as instruments of change and educators are transforming from facilitators of the learning process to "critical friends" and advisors.

- ICT tools are integrating in the pedagogical process through emancipatory action- research and problem solving methodologies and they are transformed from technical to cognitive tools, and from those, to emancipatory. 


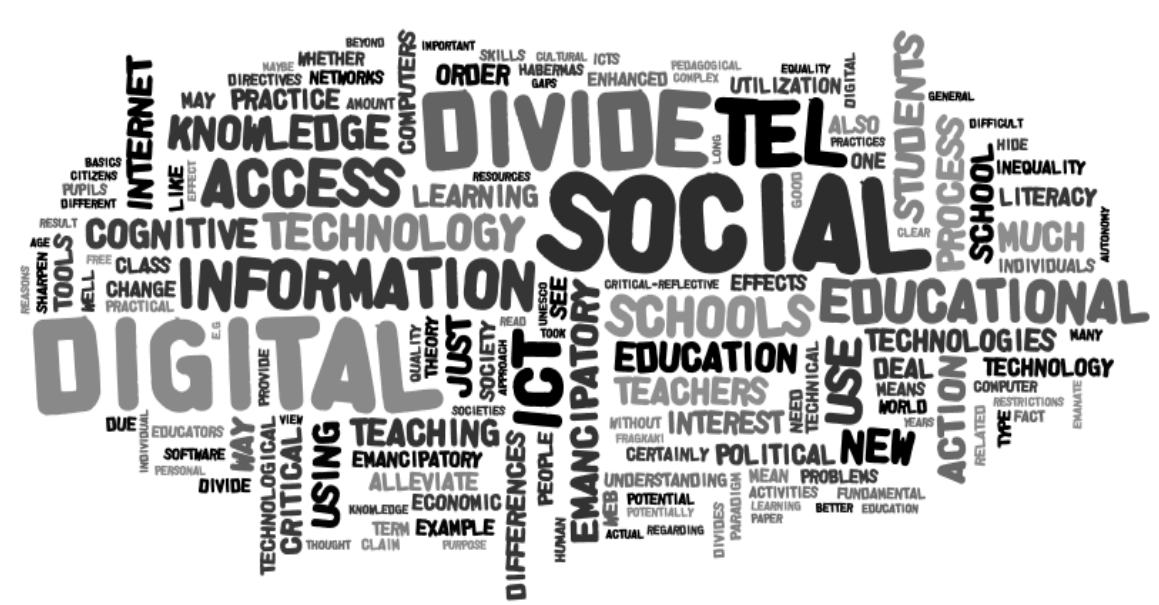

Figure 2: Emancipatory Technology Enhanced Education to digital \& social divide alleviation

\section{Practical Issues for the Emancipatory TEL paradigm}

We give some examples of concrete educational practices which, while involving the integration of TEL in schools, may well intensify the 'digital divide'. We show that more ICT is not always better and that it is easy to pay lip service to high educational curriculum goals when the actual practice of TEL in fact is a disservice. Measuring and assessing the long term social effects of TEL is particularly difficult. We propose, however, a systematic way to observe short term effects from ITC utilization in schools and present the example of an elementary school in Greece. Let's see a 'good actual practice in a non privileged but ICT e-mature school in the area of Athens, which is trying to bridge the 'digital divide' gap that caused from Internet security technology, by the way of Emancipatory TEL. Food for this practice was an authentic episode, that took place when students violated their teacher privacy, by posting on facebook a video of her the time she was teaching. Teachers should either punish the students or turn to advantage this episode and enhance them the Knowledge of laws and ethical attitudes not only through theory but mostly through praxis. They choose to use emancipatory TEL practices, regarding the distribution of personal information on the Internet, in order to skill them handling this information for data management in social networks and take the attitude of students respecting others rights. Still, we present two more practical uses of ICT. One could be described as 'bad' and the other as 'ugly', not because of their scarcity and inability to use technological tools, but because of their pedagogical utilization.

\section{The "Good":}

The educational practice "Dangers on the Internet: Knowledge, Skills and Attitudes" for children moved on many levels, materialized not only by pupils and teachers, but by parents and specialists through a collaborative teaching approach, by the context of Emancipatory Pedagogy. Pupils divided into groups, collaborated, observed, identified, recalled, organized, categorized, arranged, analyzed, explained, verified, solved, and created, technology enhanced, cloud computing open and free resources. They expressed, organized, and shared their feelings about the episode that took place integrating social network environments. They analyzed their behaviors, using 'Mind Mapping Software'. They found solutions and discovered life values that resulted from the solutions they discover, using Web.2.0. cloud -computing tools. They recorded surveys, wrote and share their data in 'google docks' and 'e-portfolios', adapting "new" and reflective ways that changed their initial negative behaviors and help them to face and solve their problems. Furthermore, the students studied at home 
relevant material from eLearning repositories, and continually they took place on conversations in their school ('flipped classroom' practice) and with the collaboration of other schools (via teleconferences) in order to deal with the problem that they had to solve. They took part in educational actions, creating posters for the competition 'Safer Internet' through team work, using creative ICT software. These actions continually took place at school, when pupils as mentors to their peers discussed with them safety internet issues and teachers conducted activities in their classrooms. Students coordinated by special scientists and as 'young reporters in action' explored the theme of 'Internet security', interviewing, recording and presenting their views and research results to their classmates. In the final stage, students, teachers, parents' scientists and all community participated in a seminar organized at school related to the studied topic. We can say that this practice was somehow a "good" one that could alleviate the "digital divide", because of the reflective, critical and metacognitive way that ICT tools integrated collaboratively by students and teachers in the educational process, through Emancipatory TEL.

\section{The "Bad":}

In another point of view, there is a different paradigm of a TEL practice. The teachers could indicate students what exactly they should do, by giving them the "right" recipes using ICT tools as well. They could for example ask them to study the 'given' information about the definition of the 'personal data validation' in default and preexamined websites (e.g. digital encyclopedias), and then ask them to study well, in order to be evaluated through 'true-false, 'crossword', and' matching TEL activities. Through this traditional way of teaching with the integration of ICT tools, teachers could transmit to their students instructions about what they should or should not do in a dangerous situation, presenting exclusively their own view (e.g. through a P.P.T presentation). Finally, teachers could evaluate them, by measuring the 'amount of the 'acquired knowledge (e.g. from a programming software) and at last they could represent the evaluation results in a graph or a pie. (e.g. using 'Excel'). In our opinion this ICT behaviorist and conservative teaching approach can sharpen the 'digital divide.TEL on the one hand can facilitate a teacher centered conservative learning, reinforcing the stamp of the technological development without taking into consideration the human, the constructivist, the critical, the creative and the emancipatory development.

\section{and... the "Ugly":}

Teachers could integrate TEL through a "good' teaching practice, but having adopted an 'ugly' perception as well, stereotyping on the examined subject, according to their personal theory and their tacit knowledge. They could for example use some relative and proper eLearning Objects (e.g. several videos on 'You Tube') for the Internet risks that they could scare and admonish the k-12 students. At best, they could explain to them, "what a child in 'facebook' could meet with' e.tc. So, they would teach students through technology to avoid and fear the technology. But, the fear is that we want? That is the constructivist way to bridge the gap? It is quite easy to make our students repeat a list of dangerous in the web. It's a total a different story to make our students understand, think about them and actually deal with them when is needed.

\section{Conclusions: "Forward to the basics"!}

If we try to 'mock' ICT, and especially the web, we can say that through the web we have much more information and the potential for much more knowledge, to many 
more people much -much quicker. And in every day talk, we have a new authority, and unfortunately, this authority also refers to anyone can be as bigot as he wants in the web. And we can go and satisfy all our need or all our greed from the web. We can have academic or other organizations, pretending that they speak about the absolute truth and finally we can have the utmost of professionalism where we find just our own vie, of our own group, of our own country. On the other side, we could use the web in school, as a lab for critical thought. The richness of the web in schools is not that it has a lot of information. The information in a plain encyclopedia it's already much more than you need at school. So, it is not the richness of the information that value, but it is the quality of the information, the unequal quality, the free of luck of quality, the controversial points, the conflicting points, that allow you to use the web as a lab for critical thought in a way that only a very reach library, or set of libraries would aloud. It encourages 'new' practices of reading and opens possibilities for constructing, reflecting and enacting new images of one 's self, by the way of the Emancipatory TEL paradigm.

Examples are nice, but the 'digital divide' is a long term trend in order for someone to claim that through education we have a positive result by alleviating parts of the 'digital divide'. We will have to evaluate it long term and see in five, ten or twenty years what happened to the people who are today elementary schools pupils, but there are some simple ways of evaluating and assessing in our schools what is the result of what we do. So, how we do evaluate an assess in our microwaves? In a microwave of a class of a school? Certainly not, by giving them multiple choice examples to answer. in default and pre-examined websites (e.g. digital encyclopedias).We are not talking about predefines technical criteria that involve "measurability" and 'effectiveness'. We are talking about a 'reasoning feedback' of the educators and their pupils, where they are going to review their own work with ICT tools, the content, the teaching and learning process, the results and the means used, in accordance to the aims that they have set, transformed and restructured, through a critical-reflective process. We are not advocating something like 'back to the basics'. We have critical - reflective thinking, and we have to recast this in the digital world. We have the politics of education, - what we were saying is that the type of education has a direct social political effect- and we have to cast this in the digital world. And finally, see again and to the role of the teacher in the digital world, as an elective-critical educator that is now more concerned with the "why" and not only with the "what" of the ICT teaching and learning process, questioning about the ethical and political impact of teaching, specifically in the micro-level teaching and generally in the macro-level teaching. So are we advocating back to basics? No, what we are saying is 'forward to the basics' through Emancipatory TEL in order to bridge what technology can divide.

\section{References}

Buente, Wayne, and Alice Robbin. (2008). Trends in Internet Information Behavior, 2000-2004. Journal of the American Society for Information Science and Technology 59(11): 1743-1760. www.interscience.wiley.com.

Cisler, S. 2000. Subtract the 'digital divide'. (2001) http://www.mercurycenter.com/ svtech/news/indepth/docs/soap011600.htm. Retrieved December 28, 2001.

Chinn, Menzie D. and Robert W. Fairlie. (2004). The Determinants of the Global 'digital divide': A Cross-Country Analysis of Computer and Internet Penetration. Economic Growth Center. Retrieved from http://www.econ.yale.edu/growth_pdf/cdp881.pdf.

Carr, W., \& Kemmis, S. (1997). For a Critical Educational Theory. Education, Knowledge and Action Research. Athens: Kodikas.

DiMaggio, P. J., and E. Hargittai. (2001). From the "digital divide"” to "digital inequality": Studying 
Internet use as penetration increases. Working Paper 19.

Europe (2012). Commission presents new Rethinking Education strategy. European Commission. Eurostat (2013). Enlargement Countries: Population and Social Conditions. European Union.

EESC (2013). Social Media and Social Networking as agents of Participatory Democracy and Civic Empowerment. European Economic and Social Committee

Eurydice (2012). Developing Challenges and Key Competences for School in Europe, Eurydice Report.

Fragkaki, M \& Hatzilacos, Th., (2012). ICT in Schools and the 'digital divide': Sharpen, Alleviate or Hide? Proceedings of the 2nd International Conference on "Critical Education", Athens 1014 July 2012.

Fragkaki, M. \& Lionarakis, A. (2011). Education for liberation: Transformative Online Models for ICT exploitation in Education. In the book titled Research on Transformative Online Education and Liberation: Models for Social Equalit.

Fragaki M. (2008). Creating an Online Learning Community for the pedagogical use of Information and Communication Technology in educational practice: Study of a Polymorphic Model with an emancipatory cognitive interest. Doctoral thesis, University of Athens.

Graham, Mark. (2011). Time Machines and Virtual Portals: The Spatiality's of the 'digital divide'. Progress in Development Studies, Vol. 11, No. 3, 211-227. Retrieved from: http://pdj.sagepub.com/content/11/3/211

Grundy, S. (2003). Curriculum: Product or Praxis (translation E. Georgiadi). Athens: Savallas Publication.

Habermas, J. (1972). Knowledge and Human Interest (2nd ed.). London: Heinemann

Hilbert, M. (2011). The end justifies the definition: The manifold outlooks on the 'digital divide' and their practical usefulness for policy-making. Telecommunications Policy, 35(8), 715-736.

Hilbert, M. (2009)"When is Cheap, Cheap Enough to Bridge the 'digital divide'? Modeling Income Related Structural Challenges of Technology Diffusion in Latin America". World Development, Volume 38, issue 5, p. 756-770

OECD (2013). Sparking Innovation in STEM Education with Technology and Collaboration: A case study of the Catalyst Initiative Centre for Educational Research and Innovation.

UNESCO (2002) Outlines Strategy to Combat 'digital divide'

UNESCO (2005) Convention on the Protection and Promotion of the Diversity of Cultural Expressions

U.S. Department of Commerce, National Telecommunications and Information Administration (NTIA). 1995. Falling through the net: A survey of the "have nots" in rural and urban America. Retrieved from http://www.ntia.doc.gov/ntiahome/fallingthru.html.

Warschauer, Mark. (2003). Technology and Social Inclusion. Rethinking the 'digital divide'. MIT Press, Cambridge Massachusetts Institute of Technology, London, England. 